\title{
La protección penal del medio ambiente. Análisis del art. 338 del Código Penal colombiano sobre minería ilegal ${ }^{*}$
}

\author{
Sebastián Felipe Sánchez Zapata** \\ (ssanch12@eafit.edu.co)
}

Artículo de investigación recibido el 16/11/2015 y aprobado el 19/02/2016.

Cómo citar este artículo:

SÁNCHEZZAPATA, Sebastián Felipe (2016). “La protección penal del medio ambiente. Análisis del art. 338 del Código Penal colombiano sobre minería ilegal". En: Trans-pasando Fronteras, Núm. 9, pp. 77-114. Cali, Colombia: Centro de Estudios Interdisciplinarios, Jurídicos, Sociales y Humanistas (CIES), Facultad de Derecho y Ciencias Sociales, Universidad Icesi.

\section{Resumen}

El estudio de la criminalidad medio-ambiental comprende todo un elenco de problemas jurídico-penales de muy difícil solución. Basta acudir a las dificultades que sobresalen al momento de definir el bien jurídico protegido, el desvalor de acción y resultado, las leyes penales en blanco, la relación de causalidad, etc. Un acercamiento, aunque sea superficial, a las dificultades ínsitas de estas categorías revela el uso que se está dando, en nuestro contexto, a la retórica apuesta del legislador por proteger concretos objetos materiales

Artículo resultado de la labor investigativa del autor como profesor invitado de la Universidad de Cádiz (España) y miembro del Programa Jóvenes Investigadores e Innovadores Colciencias 2012.

** $\quad$ Magíster y especialista en Derecho Penal Universidad Eafit. Profesor invitado y candidato a Magíster en Sistema penal, Criminalidad y Políticas de Seguridad Universidad de Cádiz (España). 
como los yacimientos mineros, las aguas y el material de arrastre. El texto, desde una perspectiva penal, expone la realidad de la minería ilegal en Colombia y las formas institucionales de reacción contra ella.

\section{Palabras claves:}

Derecho penal ambiental, minería ilegal, medio ambiente.

\section{Introducción}

Realizar un estudio sobre las cuestiones relativas a la protección penal del medio ambiente resulta un debate manido e inútil; en primer lugar, en cuanto se quiere reiterar la ineficacia de los instrumentos jurídicos diseñados para controlar los ataques contra el medio ambiente (Silva Sánchez 1997: 1714; Heine 1993: 290; Palazzo 1999: 69; Mendo Estrella 2008: 238; Lascuraín Sánchez 2005: 265; Terradillos Basoco 1996: 301), opciones que -generalmente- terminan en una epiqueya sin contenido novedoso alguno; en segundo lugar, por la escasa contribución que a esta causa podría extraerse para un país como Colombia donde cada vez más se atiende a la industrialización y tecnificación de los recursos naturales. ${ }^{1}$

El último Plan Nacional de Desarrollo (PND) 2010-2014 apostó por una fórmula de desarrollo sostenible en materia ambiental. Con un enfoque industrializado, el Gobierno colombiano presentó las actividades mineras como símbolo de modernidad, progreso y crecimiento económico. Dentro del cuatrienio se tuvo como objetivo principal lograr que el sector minero constituyera una "locomotora" de progreso y que se convirtiera a este renglón de la economía en uno de los pilares fundamentales de las finanzas públicas. Dicho objetivo, enmarcado también con el propósito de impulsar otras importantes áreas -como la innovación, ciencia y tecnología- no se logró; las incontrolables implicaciones económicas y jurídicas terminaron cuestionando la locomotora minera. Aunque este sector, sin duda, jalona el progreso del país, como en cualquier otro ámbito de actuación, sus complejidades técnicas requirieron un diagnóstico mucho más incisivo, un cambio de estrategia, más que un aumento teórico y simbólico.

Naturalmente, como en cualquier otro conflicto de carácter ambiental, el asentamiento de la industria minera encuentra apoyo en cierto sector económico que entiende este

1 Para revisar un recorrido de la jurisprudencia de la Corte Constitucional de Colombia sobre consulta previa en casos de minería que involucra comunidades indígenas y tribales, consultar Abello (2012). 
renglón de la económica como oportunidad de desarrollo, generación de puestos de trabajo, progreso industrial, es decir, generación de riqueza; pero, un planteamiento mucho más crítico percibe y pone de manifiesto los aspectos negativos de la industria, el "lado oscuro de ese progreso tecnológico" contra el medio ambiente (Esteve Pardo 2006: 7). Esta pírrica concienciación, no hace primar por encima de cualquier otra consideración la defensa del medio ambiente; al contrario, realza las dificultades de cómo y hasta qué punto proteger el medio ambiente, cuestión que se afinca en imprecisiones políticas con intereses de la más diversa clase.

El art. 107 PND propuso como deber del Gobierno implementar una estrategia para diferenciar la minería informal de la minería ilegal, esta última, una de las mayores preocupaciones sociales del país en tanto amenaza la paz, seguridad, gobernabilidad y economía. En la minería ilegal confluyen infinidad de factores, difícilmente solucionables con una formulación normativa: la escasa presencia del Estado en los territorios mineros, el nulo control de las autoridades ambientales y la difícil situación de orden público (sumado al hecho que, a día de hoy, es la mayor fuente de financiamiento y enriquecimiento de los grupos armados ilegales) ${ }^{2}$, reproduce rápidamente "la nueva cara del narcotráfico" y reafirma el carácter simbólico de las normas que intentan proteger este interés.

Como es palmario, lo anterior ha sido caldo de cultivo para la elaboración de estrategias jurídicas de múltiple cariz jurídico. ${ }^{3}$ Específicamente, el Código Penal colombiano (CP) consagró en el Título XI rubricado "De los delitos contra los recursos naturales y el medio ambiente", varias disposiciones protectoras entre las que se encuentra el art. 338, tipo que concibe la extracción ilícita de yacimiento minero y otros materiales ${ }^{4}$, como una

2 No sólo porque los alzados en armas reciben rentas por la defensa del negocio minero, a través de las "vacunas" o "el ordeño", bien sea exigiendo una parte de la producción bruta de la mina o una cuota por cada máquina de que disponga el minero, sino porque se provocan graves daños - en muchos casos irreversibles- a la salud de la población, al medio ambiente y los recursos naturales (pérdida de cobertura vegetal y el suelo fértil, contaminación de recursos hídricos, alteración de ecosistemas naturales y graves afectaciones a la biodiversidad).

3 En Colombia existen un cúmulo de disposiciones normativas que tienen el propósito de frenar los estragos de ésta actividad ilegal: sólo por mencionar, los arts. 79, 80 de la Carta Magna, el art. 60 de la ley 99 de 1993 , el art. 165 de la Ley 685 de 2001, el art. 106 de la ley 1450 de 2011, el art. 58 de la ley 141 de 1994, la Decisión 774 de la Comunidad Andina de Naciones, etc.

4 Se entiende por yacimiento minero, según el art. 8 del Código de Minas (CM), la acumulación o concentración natural de una o más sustancias minerales o fósiles, rodeadas de materiales no aprovechables, utilizables como materia prima o como fuente de energía, que se encuentra en el subsuelo o en la superficie terrestre y cuyo volumen 
modalidad delictiva que atenta contra aquel el medio ambiente. El artículo, empleado para prevenir y remediar el daño ambiental y los efectos adversos en los que se podría incurrir a causa de prácticas no avaladas, consagra:

\begin{abstract}
Artículo 338. Explotación ilícita de yacimiento minero y otros materiales. El que sin permiso de autoridad competente o con incumplimiento de la normatividad existente explote, explore o extraiga yacimiento minero, o explote arena, material pétreo o de arrastre de los cauces y orillas de los ríos por medios capaces de causar graves daños a los recursos naturales o al medio ambiente, incurrirá en prisión de treinta y dos (32) a ciento cuarenta y cuatro (144) meses y multa de ciento treinta y tres punto treinta y tres (133.33) a cincuenta mil (50.000) salarios minimos legales mensuales vigentes. Penas aumentadas por el art. 14 de la Ley 890 de 2004, a partir del 1 de enero de 2005.
\end{abstract}

La defensa de los recursos naturales y del medio ambiente desde el orden penal empezó a concebirse en Colombia con la expedición del título III BIS, capítulo primero, del CP de 1980. Durante aquellos años, el estatuto - que de forma deliberada trasplantó la legislación que a mediados de los ochenta regía en España-, ${ }^{5}$ concebía una adelantada protección de los recursos naturales y el medio ambiente. ${ }^{6}$ Lo anterior era sólo un exiguo reflejo de la protección penal del ambiente en materia internacional que contaba ya con una base consolidada y que permitía hablar de una "historia respetable". 7 De modo que,

es tal que puede ser explotado con fines económicos. Se entenderá por mina (art. $10 \mathrm{CM}$ ) el yacimiento, formación o criadero de minerales o de materias fósiles útiles y aprovechables económicamente, ya se encuentre en el suelo o el subsuelo. A los mismos efectos, se entenderá por mineral la sustancia cristalina, por lo general inorgánica, con características físicas y químicas propias debido a un agrupamiento atómico específico.

5 Colombia ha sido un país fiado de la trasmutación jurídica de las normas y Códigos en general. La incorporación acrítica de estas disposiciones normativas, a partir de interpretaciones trasmutadas sobre los contextos en que éstas han tenido lugar, ha facilitado la adopción de una serie de particularidades jurídicas, políticas e históricas que obedecen a elementos propios de otras culturas. En materia penal puede consultarse, por todos: Terradillos Basoco (1999); Sotomayor Acosta (1999: 92).

6 La rúbrica del Título III BIS, Capítulo primero del CP de 1980 "De los delitos contra los recursos naturales y el medio ambiente" fue modificada por el art. 18 de la Ley 491 de 1999 hacia "De los delitos contra los recursos naturales y el ambiente", aunque el CP volvió a la rúbrica primigenia.

7 En Alemania Kühlen (1993); Hassemer (1995: 23); Heine (1993: 289); Hefendehl (2008); Schünemann (2002: 203). En Italia Bricola (1984: 3). En España Bacigalupo (1992: 193); Berdugo Gómez de la Torre (2008: 997); Conde-Pumpido Tourón (1992: 13); De la Cuesta Aguado (1995: 31); De la Mata Barranco (1996: 47); De 
la convicción del legislador de adecuar el Derecho penal a ésta acuciante preocupación terminó siendo una muestra más de la ineficacia de los instrumentos jurídicos en dicha tutela: los tipos penales se aplican poco, no se persiguen las agresiones graves ni las conductas de bagatela y las más flagrantes dan lugar a excesivas reacciones penales; son bajos, por no decir inexistentes, los supuestos de judicialización o criminalización y peor aún, cada vez eran más elevados los daños medioambientales.

Sabido es que el recurso al Derecho penal como mecanismo de protección del ambiente no es un mecanismo novedoso y tampoco constituye, en modo alguno, el único instrumento, ni tan siquiera el básico. ${ }^{8}$ Asimismo, resulta trivial volver a señalar los problemas que aparejan las estrategias simbólicas para el Derecho penal. ${ }^{9}$ Por consiguiente, el "engaño" y la "apariencia" de los fines descritos en la regulación normativa terminaron siendo distintos a los que se esperan de hecho; no tardó en desplazarse la función esencial de protección de bienes jurídicos hacia una función exclusivamente simbólica de "promoción social de valores", de manera que se absolutizó el bien jurídico del medio ambiente y se le convirtió en un criterio incriminador del legislador penal (Hassemer 1999), ${ }^{10}$ desechando su función delimitadora.

la Cuesta Arzamendi (1999: 30); Hormazábal Malareé (1992: 51); Terradillos Basoco (1992: 79); Silva Sánchez (2012: 15); Paredes Castañón (2013: 751).

8 La tutela del ambiente pasa por una acción integrada desde diversos ámbitos que no son de cariz jurídico. Aunque el Derecho penal ambiental haya emergido como piedra angular en el sistema de protección y constituya el último eslabón de la pirámide en donde podrá desplegar sus efectos, existe un cúmulo de disposiciones de distinto rango que regulan la protección del ambiente y los recursos naturales, abanico legislativo, incluso, de orden internacional. Al respecto: Terradillos Basoco (2004: 219).

9 Entiende Hassemer (1995: 23) que, en sentido crítico, "simbólico" es un Derecho penal en el cual las funciones latentes predominan sobre las manifiestas. Por funciones manifiestas entiende las condiciones objetivas de realización de la norma, las que la propia norma alcanza en su formulación: una regulación del conjunto global de casos singulares que caen en el ámbito de aplicación de la norma, esto es, la protección del bien jurídico previsto en la norma. Las funciones latentes, a diferencia, son múltiples, se sobreponen parcialmente unas a otras y son descritas ampliamente en la literatura: desde la satisfacción de una "necesidad de actuar" a un apaciguamiento de la población, hasta la demostración de un Estado fuerte. Al respecto: Alonso Álamo (2008: 36); Hormazábal Malareé (1992: 51); Escajedo San Epifanio (2007: 39); Müller-Tuckfeld (2000).

10 El derecho penal deja de ser un instrumento de reacción frente a los atentados más graves y se transforma en el instrumento de una "política de seguridad". Con ello pierde su posición en el conjunto del ordenamiento jurídico y se aproxima a las funciones del derecho civil o administrativo, pasando a ostentar una función simbólica que afecta a las garantías tradicionales del Estado de Derecho. No es este el espacio para justificar la vuelta a un "derecho penal "clásico", o "nuclear". Lo cierto es que la distinción entre el Derecho penal clásico y el moderno, en 
Los anteriores problemas en un contexto de deficiente criminalización primaria y manifiesto carácter desigual y estigmatizador de la selección secundaria (respecto a los objetos protegidos, las conductas y sujetos perseguibles), dieron paso a que los delitos contra al medio ambiente asentaran aquella función simbólica, dejando inmunes parcelas de comportamientos (sobre todo, en el seno de grupos armados al margen de la ley), castigando otros que servían para encubrir dicha inmunidad y actuando sólo como un refuerzo de la tutela administrativa. Pues bien, el art. $338 \mathrm{CP}$, que mucho desdice de la publicitada "minería responsable", no ha contribuido a brindar una conexión entre las decisiones administrativas y la cruel realidad. Inevitablemente, esto conduce a preguntarse cuál debería ser la forma ideal para proteger el medio ambiente en Colombia, específicamente, qué estrategias jurídico-penales deberían emplearse para mitigar los efectos adversos de la minería ilegal.

Con este propósito, el texto se aproxima al desarrollo de una protección penal del medio ambiente en Colombia, estudiando con detenimiento la técnica legislativa empleada para la confección del art. 338 y señalando cuál debería ser el contenido más recomendable para el bien jurídico medio ambiente, de cara a una respuesta penal mucho más completa y eficiente. Claro está que al momento de elaborar e interpretar la ley penal no se hace un estudio a fondo de la técnica legislativa y por ello se dice que la eficacia del Derecho penal queda notoriamente disminuida (De la Mata Barranco 1996: 33; Kühlen 1993: 697; Hormazábal Malareé 1992). Sin embargo, estudiar el número de comportamientos que atentan contra el medio ambiente y sobre todo, el grado de aplicación efectivo de las normas es un paso de inicial concreción para atar el Derecho penal y el administrativo a la indecorosa realidad.

De los anteriores problemas se sabe poco. A causa de la cifra negra de la criminalidad, la escasez de denuncia en éstos tipos y el hecho de catalogar estos supuestos como conductas socialmente adecuadas, nadie tiene cifras exactas de cuántas de las Unidades de Producción Minera (UPM) que están censadas se encuentran tomadas por grupos armados ilegales; ni siquiera, cuántos de los miles de mineros informales están bajo su yugo o cuántos de éstos se dedican al negocio sobre la base del conocimiento de la dis-

ocasiones es gaseosa "ya que la mayoría de los rasgos, que se dice, caracterizan al actual proceden del clásico". Al respecto: Portilla Contreras (2008: 286). 
posición. Tampoco se conoce cuál es la influencia real de la sanción penal en el proceso de motivación de los sujetos a los que se dirige la norma. De lo que sí existe más certeza es que la eficacia de la norma -medida en función de la prevención de comportamientos muy graves- es notoriamente reducida por las altas zonas de impunidad y la evidente debilidad del sistema penal colombiano.

Desde ésta perspectiva, la constatación manifiesta del fracaso del Derecho penal del medio ambiente o de su funcionamiento sólo a nivel simbólico, impide la puesta en práctica de una auténtica política medio-ambiental, razonable, eficaz y eficiente. Pero, paradójicamente, ello constituye el primer paso hacia una mejor protección del objeto que se dice querer amparar (Silva Sánchez 1997: 1720). Hoy, más que nunca resulta procedente ahondar en el estudio de las razones que desde el punto de vista jurídico -también del axiológico o sociológico(González-Ripoll Garzón 1992: 77-79). reclamen nuevos análisis de los tipos medioambientales, así como de las normas administrativas y procesales al respecto. Aunque la eficacia del Derecho Penal sea notoriamente reducida, este dato, por sí solo, no autoriza a afirmar la absoluta inidoneidad del precepto, sino que impone la necesidad de depurar la técnica tipificadora utilizada para superar su tosquedad, ${ }^{11}$ y una vez hecho esto, empezar a articular estrategias político-criminales mucho más completas y coherentes. Las incorrecciones de técnica legiferante no pueden llevar a ignorar los argumentos que avalan la criminalización; muchos menos justifican la reticencia que se detecta en ciertas resoluciones judiciales (Terradillos Basoco 2008: 367). En definitiva, la discusión dogmática sobre el alcance y límites de la protección penal del medio ambiente, antes como ahora, debe seguir su curso. Siendo múltiples los factores de análisis, se centrará la atención en analizar algunos aspectos jurídicos del art. 338 CPC, exclusivamente, los relativos a la conducta típica y al bien jurídico protegido, dejando para una próxima oportunidad, las dificultades ínsitas al desvalor de acción y resultado, las leyes penales en blanco, y el principio del non bis in idem, etc. Evidentemente, no se pretende un análisis exhaustivo de estas cuestiones, imposible de abarcar en un espacio tan reducido, pero sí poner de relieve el planteamiento crítico del problema.

\section{Minería ilegal en Colombia: impacto y desafíos}

11 Entiende que los instrumentos jurídico penales, además de ser poco efectivos, son demasiado toscos: De la Cuesta Aguado (1995a: 130). 
La protección jurídica del medio ambiente es ciertamente una cuestión relativa. Depende del grado de conciencia ambiental que exista en un territorio determinado y de la capacidad de gestión y aplicación de las normas protectoras de un Estado. Esto es algo que, a su vez, varía en función de las condiciones sociales, políticas, económicas del momento en una determinada sociedad (Silva Sánchez 2012: 15). ${ }^{12}$ En concreto, la protección que se otorgue al medio ambiente en Colombia está condicionada principalmente por las posibilidades económicas efectivas que posee el territorio y por las limitaciones de orden público que ponen en vilo al país.

Cuando de crecimiento económico se trata, el sector minero alcanza su mayor impacto. Según las cifras del DANE, la participación del PIB minero energético para el primer semestre de 2012 fue el 14.8\% agrupando la producción de petróleo, carbón, minerales metálicos y no metálicos, energía eléctrica y gas (ANDI 2012: 28). A esto se añade que éste renglón de la economía ha generado un importante flujo de divisas provenientes de dos grandes fuentes: las exportaciones y la inversión extranjera directa. Las ventas externas pasaron de US $\$ 5.881$ millones en el año 2000 a US $\$ 40.363$ millones en el 2012; y, la participación dentro de las exportaciones totales, igualmente lograron un aumento significativo, alcanzando $66 \%$ en 2012. Con respecto a la IED, en el 2000 se recibieron inversiones por valor de US \$136 millones, en 2005 por US $\$ 3.031$ millones y para el año 2011 por US $\$ 8.009$ millones. A su vez, la participación dentro de la IED total pasó de un 6\% en el 2000, a un casi 60\% en 2011 (ANDI 2012: 26). Para el primer semestre de 2012, la inversión recibida en petróleo, hidrocarburos y minería ascendió a US $\$ 5.227$ millones, con un crecimiento del 17\% frente a igual período de 2011. En definitiva, al comparar el primer trimestre de 2013 con el periodo inmediatamente anterior (DANE 2013: 15), el sector de minas y canteras registró un crecimiento del valor agregado en 1,7\% (DANE 2013: 17).

Sin embargo, el "boom" de la minería que atrajo el interés de inversionistas estimulados por la facilidad para adquirir licencias y permisos ambientales (bastaba con mostrar la cédula de ciudadanía para hacerse al derecho de explorar sobre un determinado territorio) hizo que el área titulada pasara de 1,1 millones de hectáreas $(0,98 \%$ del territorio

12 Se entiende que no puede hablarse de una protección absoluta del medio ambiente, constitucionalmente protegido, sino relativa (Cugat Mauri 2008: 447). 
nacional) en el 2002, a 8,4 millones de hectáreas (casi el 10\% del territorio) en el 2009 y más de 40 millones de hectáreas adicionales ( $36 \%$ del territorio nacional) en estudio (Acosta 2012: 1). Esta preocupación se mezcló con un desafío mucho peor: el interés de las mafias organizadas para convertir a la minería en combustible de guerra.

Desde hace ya algún tiempo, la prioridad del Gobierno colombiano se ha dirigido a atacar el problema de la minería ilegal intentando frenar el financiamiento de los grupos armados al margen de la ley. La minería ilegal, entendida como aquella que se realiza por fuera de la normatividad y con la participación de mafias, bandas criminales o grupos armados ilegales en el país, debe diferenciarse de la minería ilícita, actividad que se desarrolla sin reglamentación alguna ora por no contar con un título minero ajustado a derecho ya por carecer de autorización administrativa; ambas ab initio son ilegales y pueden causar los mismos efectos al medio ambiente, sólo que aquella merece más atención por ser más difícil de distinguir, repeler y mitigar. Sin embargo, para entender éste tipo de minería ilegal (que sería el género) impera descomponer su especie: la minería ilícita.

Son variados y problemáticos los tipos de minería existentes en Colombia: por un lado está la minería de subsistencia desarrollada por personas naturales que dedican su fuerza de trabajo a la extracción de algún mineral mediante métodos rudimentarios, normalmente, en asocio de otra persona para generar ingresos de subsistencia. En general, esta técnica se conoce como barequeo o aquella explotación de pequeña minería de aluvión y se entiende que esta actividad se reduce al lavado de arenas por medios manuales sin ninguna ayuda de maquinaria o medios mecánicos y con el objeto de separar y recoger metales preciosos contenidos en dichas arenas. El ejercicio de éste tipo de minería ocasional (casi siempre, sin título minero) requiere, según el art. 155 de la ley 685 de 2001 (CM), la inscripción ante el Alcalde del pueblo y si se efectúa en terrenos de propiedad privada, la autorización del propietario (art. 156).

El barequeo debe diferenciarse de otra tipología de minería ocasional denominada "transitoria de minerales a cielo abierto" (art. $152 \mathrm{CM}$ ), realizada por los propietarios de una superficie, en cantidades pequeñas, a poca profundidad, por medios manuales y sin una concesión por parte del Estado; este tipo de minería tiene como destino, ordinariamente, el consumo de los mismos propietarios en obras y reparaciones de sus viviendas e instalaciones. La diferencia entre ambas radica en el destino comercial del barequeo (a 
fines de subsistencia) y la obligación expresa de conservar, reparar, mitigar y sustituir los efectos ambientales negativos que se puedan causar por la minería transitoria, esto es, la readecuación de los terrenos explotados, obligación que no tiene razón de ser en el barequeo por la mínima ofensividad de los medios empleados.

Ahora bien, atendiendo al régimen jurídico del ordenamiento es dable diferenciar entre la minería legal y la ilegal. La minería legal es aquella minería amparada por un título minero que otorga el derecho a explorar y explotar el suelo y subsuelo minero, propiedad del Estado colombiano. ${ }^{13}$ Esta minería -que deberá estar inscrita en el Registro Minero Nacional- es una minería formal, es decir, una minería conformada por unidades de explotación minera de tamaño variable, entre ellas, empresas legalmente constituidas. Correlativamente, la minería informal es aquella constituida por unidades de explotación pequeña y medianas y sin ningún tipo de registros contable y sin título minero. La mezcla de estas tipologías ha dado lugar a que la definición de la minería ilícita ${ }^{14}$ presente características de unas y otras:

Es una minería que no cuenta con el título minero o que incumple con sus requisitos al tiempo que puede presentarse tanto en unidades legalmente constituidas como en unidades sin ningún registro contable o de manera individual, de manera ocasional o permanente, por intermedio de actividades del barequeo o la informalidad, con o sin el control de grupos organizados al margen de la ley.

Cabe aclarar que no toda minería ilícita con el Estado es irrespetuosa con el medio ambiente; como tampoco toda minería lícita es respetuosa con esta tutela. La ilicitud no sólo deriva del incumplimiento del precepto normativo, sino que se desprende de la valoración de las consecuencias que tal actividad genera para el medio ambiente, esto es, del grado de lesividad para con el bien jurídico. En este orden de ideas, la minera ilegal (en la que participan actores armados al margen de la ley) genera, a causa del escaso control efectivo del Estado y de la confluencia de métodos irreparables e ilegales, un reproche

13 Según los arts. 80, 332, 334, 360 de la Constitución Política de Colombia, el propietario del suelo y subsuelo es el Estado. Su deber es planificar el manejo y aprovechamiento de los recursos naturales.

14 Que según la definición de la Ley 685 del 2001, consiste en trabajos de exploración, extracción o explotación de minerales de propiedad nacional o privada, sin el correspondiente título minero o sin la autorización del titular de dicha propiedad. 
mucho mayor que la minería ilícita puesto que absorbe casos más graves y de incontrolables consecuencias para el medio ambiente.

\section{Factores intrínsecos y extrínsecos}

La primera consideración a efectuar en el análisis del art. 338 CP deviene de las dificultades aplicativas que obedecen a la técnica legislativa utilizada. Principalmente, los aprietos se verifican a partir de la estructura interna del precepto penal, pero ello no excluye verificar otra serie de factores extrínsecos. Ambos factores (intrínsecos y extrínsecos) son los que, por un lado, contribuyen a formar la impresión de ineficacia e inestabilidad en el ámbito del Derecho penal del medio ambiente y por otro, resaltan los problemas del diseño de estrategias propias de este mecanismo de control en la legislación, en el derecho sustancial y procesal.

Los factores intrínsecos (del bajo nivel de aplicación y de eficacia del Derecho penal del medio ambiente) se derivan de la propia estructura de este sector del ordenamiento jurídico de manera que, para suprimirlos o rebajar su relevancia, sería necesario trasformar dicho sector de forma significativa. A su turno, los factores extrínsecos, pueden ser alterados mediante la modificación de otros elementos (del sistema penal -proceso, organismos de persecución, etc.- del resto del ordenamiento jurídico o de la estructura social), sin necesidad de tocar el propio Derecho penal (sustantivo) del medio ambiente. Mientras que la eliminación de los factores intrínsecos al propio Derecho penal del medio ambiente contribuyen a su ineficacia y exigen soluciones de índole técnico-jurídica, la eliminación de los factores extrínsecos ha de encararse mediante otra clase muy diferente de soluciones: soluciones políticas (no juridificadas), principalmente (Paredes Castañón 2013; Morales Prats 2008).

Para los primeros, no basta con la formulación de normas sancionadoras abstractas, sean administrativas o penales, si previamente no se ha diseñado e instrumentalizado una política social global sobre la materia de que se trata (Hormazábal Malareé 1992: 52). Por ello, afrontar los problemas relacionados con la delincuencia ambiental se inicia con el enfrentamiento de la técnica empleada por los legisladores. El legislador parte de un consenso sobre ciertos valores que debe proteger el derecho penal pero al momento de exigir el diseño de una política ambiental integral, los objetivos, estrategias y técnicas de 
intervención terminan diluyéndose, lo que apareja mucha simbología pero escasas implicaciones prácticas. Pero el legislador no es el único. En el orden interno se debe acudir al análisis de la jurisprudencia, factor de examen que se dificulta en demasía por la indeterminación de los conceptos empleados en los propios tipos penales (peligro, gravedad y medio ambiente $)^{15}$ y por la escasa verificación judicial del artículo; súmense las dificultades relacionadas con el ámbito de la prueba y particularmente, un criterio estable sobre los requisitos, garantías y medios técnicos a observar. De lo anterior no parece preciso inscribir el problema exclusivamente a la técnica legislativa o a la interpretación judicial.

Aún más, el mayor problema a la hora de efectuar un balance sobre el rendimiento del art. $338 \mathrm{CP}$ concierne a la dificultad ínsita de la propia definición hacia un modelo que se observa con respecto a una disciplina jurídica extrapenal; con esto quiero decir que la practicabilidad y eficacia del precepto penal depende en gran medida del propio desarrollo e implantación de la legislación ambiental extrapenal (Morales Prats 2008: 1035), espacio que se encuentra disperso en una ingente normativa, conduciendo a una deficiente coordinación entre las autoridades protectoras y a dificultades valorativas e interpretativas al punto de proclamar la inexistencia de una política integral en materia ambiental.

Por otro lado, la lógica empleada en los factores extrínsecos es contraria a la empleada en los factores intrínsecos. Aquí se trata de dar soluciones que suelen recurrir a la política y la criminología. En general, los estudios sobre la criminalidad medioambiental señalan que ésta es, prácticamente, la criminalidad de los grupos poderosos (criminalidad a gran escala de grupos y empresas económicas), en la mayor parte de las ocasiones, protagonizada por personas bien integradas. ${ }^{16}$ No obstante, el perfil del delincuente medioambiental colombiano encaja en el lumpen de los sectores más pobres, marginados y excluidos de la clase trabajadora. El delincuente medioambiental en Colombia no es un delincuente de clase alta, media o de los sectores más prósperos del proletariado; normalmente, estos sectores - quizás por la irresponsabilidad penal de las personas jurídicas- escapan a la judicialización, recayendo la penalidad en un perfil socioeconómico re-

15 Las condiciones concretas que cada sentencia acaba exigiendo para la condena varían: a veces parece bastar con la realización de una actividad estadísticamente peligrosa; otras veces, parece más bien, que se necesita algún efecto de dicha actividad; y a veces, parece que es necesario un resultado físicamente tangible y conceptualmente separable de la propia acción (Paredes Castañón 2013).

16 Por todos, Terradillos Basoco (2009). 
presentado por hombres (afrocolombianos, caribeños, indígenas), analfabetos o que han alcanzado estudios primarios, residentes en territorios cercanos a las minas, que trabajan a diario, generalmente en un turno por día de 8 o más horas, contratados a destajos y que no cuentan con otra actividad que les devengue mejores márgenes productivos (Anuario Estadístico Minero Colombiano 2012: 35).

En términos cuantitativos, el posible impacto de la minería ilícita depende de la cantidad de infracciones y del aceleramiento continúo de daños representado por tales conductas. Durante los años 2011 y 2012 de los 14.357 UPM (unidades de producción minera) detectadas, tan solo el $37 \%$ de ellas tenían título minero, mientras que el 63\% no lo tenían (Censo Minero Departamental Colombiano 2012: 11). De acuerdo al censo minero departamental realizado por el Ministerio de Minas y Energía (MME) en 23 departamentos del país, actualmente más de la mitad de éstas operan sin título minero, lo que no implica imbricar la minería informal con la ilícita pero sí, dar por sentado la magnitud del problema. A esto se suma la escasez de denuncias y la falta de interés por investigar las pocas que existen. ${ }^{17}$ Es sabido que el número de casos policialmente registrados depende de la relación entre comportamiento de control y comportamiento de denuncia, ambos "mecanismos de neutralización que no se llevan a cabo ni por al ciudadano (porque se declara incompetente, porque es indiferente) ni por la autoridad (porque no está segura de si se trata o no de una destrucción legal del medio ambiente). En consecuencia, las autoridades parten de una elevada cifra negra. Obviamente, dada la dificultad de acceso a ciertas zonas que impide un efectivo control, desde el punto de vista intrínseco como desde el extrínseco, queda patente la debilidad de la norma para evitar los daños que se pueden ocasionar al medio ambiente. En síntesis: cuando se alude

17 Las autoridades o entidades formales de control no persiguen con la misma tenacidad éste tipo de conductas y cuando, pese a todo, visualizan una determinada conducta como atentatoria contra el medio ambiente, es porque la conducta ostenta gran magnitud y ha causado ya resultados no deseables. Dado que el daño ambiental no es necesariamente uno perceptible a simple vista y dado que es frecuente que en él converjan causas diferentes, la preparación adecuada de los órganos de investigación para obtener pruebas idóneas sólo resulta posible en la medida que se conozca la técnica de tipificación. Sólo así se podrán definir los protocolos de actuación y persecución penal. Para perseguir delitos se necesita una asignación suficiente y racional de recursos (humanos, técnicos, económicos), aspectos que tendrán mejorarán el nivel de eficacia de la persecución penal. Paredes Castañón (2013). En España, propone una policía especializada que permita dotar de mayor efectividad la investigación de los delitos medioambientales. Conde-Pumpido Tourón (1992: 36) 
a la ineficacia del Derecho penal en la tutela del medio ambiente, la troika (legislación, jurisprudencia, administración) componen esta pródiga manifestación.

\section{Análisis jurídico}

Para analizar los elementos típicos del art. 338 CP se partirá de la confluencia de varios elementos trascendentales para la confección de cualquier estructura típica: la conducta típica y el bien jurídico protegido. El análisis se realizará tomando como referencia, la aspiración político criminal de sancionar conductas destinadas a un aprovechamiento irracional de los recursos naturales, adquiriendo especial trascendencia la protección de las explotaciones mineras cuyas actividades productivas incontroladas pueden producir daños irreversibles para el medio ambiente. Sobre este punto, la doctrina española ya se ha pronunciado porque su CP incluye comportamientos penalmente relevantes como las extracciones $^{18}$. Veamos cada uno:

La conducta. En lo que se refiere a la conducta, el tipo describe que ésta consiste en explotar, explorar, extraer yacimiento minero, o explotar arena, material pétreo o de arrastre de los cauces y orillas de los ríos, siempre que infrinja la normativa medioambiental y revista gravedad tal que sea susceptible de causar daños a los recursos naturales o al medio ambiente. Para describir la conducta prohibida el legislador ha optado por tres verbos cada uno de ellos con diferentes significados.

Así, mientras que con el uso del verbo explotar se alude a la utilidad para beneficio propio, por lo general de modo abusivo, de las cualidades o riquezas de los yacimientos, arenas, materiales pétreos o de arrastre, con el verbo extraer se hace referencia a poner fuera de lugar en que se encontraban los anteriores materiales. Con explorar el legislador colombiano se refiere al reconocimiento, identificación y registro de tales zonas. Tanto la explotación, exploración como la extracción pueden llevarse a cabo de forma directa o indirecta, lo que permite señalar como comportamientos típicos tanto la ejecución material (personal) como el dar la orden para que otro las ejecute (conjuntamente o como instrumento).

18 Las extracciones y excavaciones, que suponen la acogida de modalidades de explotación irracional, representan ámbitos cubiertos de protección en España a partir de 1995. Cfr. Silva Sánchez (2012: 59). 
Por otro lado, así el tipo delictivo venga configurado por la concurrencia de una acción de carácter positivo - consistente en un hacer-nada obsta para que de la redacción legal se entienda incluida en el tipo la comisión por omisión, comportamiento que consistiría en dejar que se ocasione la explotación, exploración, o extracción, sin hacer nada para evitarlo y siendo garante. De este modo, tendrían que analizarse los casos en que el sujeto deja, tolera, permite que se produzca uno de los verbos rectores y se constata la presencia de los demás elementos exigidos con carácter general tanto en el 338 como en el art. $25 \mathrm{CP}$.

Como es palmario, por explotar se entiende el empleo económico de la riqueza que las minas contienen; desde un punto de vista estrictamente normativo, este verbo puede entenderse como la utilidad que se deriva de las cualidades ínsitas a los yacimientos mineros. El Código de Minas define la explotación como el conjunto de operaciones que tienen por objeto la extracción o captación de los minerales yacentes en el suelo o subsuelo, su acopio y beneficio, definición que superpone ambos verbos rectores.

Por extracción es dable entender el proceso de separación, molienda, trituración, lavado, concentración y otras operaciones similares (como la lixiviación) a la que se somete el mineral para su posterior utilización o transformación. Por su parte, explorar consiste en reconocer, registrar, inquirir o averiguar con diligencia una cosa o un lugar, generalmente, a partir de una serie de estudios, trabajos y obras necesarias para establecer y determinar la existencia y ubicación de los minerales -en cantidad y calidades económicamente explotables- la viabilidad técnica para su extracción y el impacto que sobre el medio ambiente y el entorno social puedan causar estos trabajos y obras. Estas conductas pueden realizarse en una serie de espacios determinados (atmosfera, suelo, subsuelo, aguas terrestres, subterráneas o marítimas o de alta mar, con incidencia incluso en espacios trasfronterizos).

Con el afán de incluir dentro del tipo todas las modalidades comisivas a través de un catálogo de verbos excesivamente amplios y que abarcaran exhaustivamente todos los escenarios posibles, no sorprende que el artículo no termine siendo una técnica adecuada. El recurso a éste listado de acciones genera el efecto inverso: que frente al objeto material protegido queden por fuera conductas no previstas o no imaginadas. Más llamativo que la exhaustividad del legislador -animada por el loable intento de no dejar por fuera ningún tipo de comportamiento que cause daños- es la elaboración de un precepto de estructura compleja con la descripción de tres conductas genéricas que deben conducir a que en 
ciertos lugares (yacimientos mineros, cauces y orillas de los ríos), se puedan producir graves daños a los recursos naturales o al medio ambiente.

Según la descripción gramatical del tipo se pueden concitar dos consecuencias: que la explotación, exploración o extracción sólo se puedan concebir en los yacimientos mineros porque ello se separó por medio de una coma de la explotación de arena, material pétreo o de arrastre de los cauces y orillas de los ríos; y que, necesariamente, los medios deben ser capaces de causar graves daños a los recursos naturales o al medio ambiente, disyuntiva que conduce a una situación en la que debe elegirse entre dos opciones, con el riesgo de confundir el objeto material y el objeto jurídico o interés tutelable. ${ }^{19} \mathrm{~A}$ lo anterior habría que añadir que la interpretación del artículo es el reflejo de una descuidada técnica legisladora que, en el peor de los escenarios, podría encuadrarse en un concurso (aparente) con otras disposiciones del mismo Título XI, traduciéndose ésta situación en una preocupante inseguridad jurídica para el ciudadano receptor de la norma.

En definitiva, frente a la variedad de acciones descritas en el tipo -cada una de ellas con su propio significado y definición- lo que debe rescatarse es que éstas sean capaces de causar graves daños a los recursos naturales o al medio ambiente. Y, esto debe ser de tal entidad que sea posible distinguir la mera infracción administrativa. El artículo además de ser un delito común (no exige la concurrencia de ninguna condición, cualidad o relación especial para ser sujeto activo), es un tipo mixto alternativo: ello supone que si se realizan simultánea, e incluso sucesivamente, varias de las acciones típicas (v.gr. extracción y explotación) estaríamos ante un solo delito, sin perjuicio de que en la determinación de la pena pudiera tenerse en cuenta la mayor o menor gravedad del hecho atendiendo a estas circunstancias. No se olvide que la referencia legal a las conductas de explotación, extracción y exploración determina que la puesta en peligro del bien jurídico -núcleo del artículo-deba producirse a través de medios -o mejor, procesos resultativos-determinados

19 "El medio" es un elemento que cualifica el tipo, pues aumenta o disminuye la idoneidad lesiva del comportamiento. En estos supuestos se debe probar que ese medio, efectivamente, ha generado o aumentado la idoneidad lesiva del comportamiento en relación con el bien jurídico protegido. Lo anterior no implica desechar el examen de idoneidad cuando se empleen medios evidentemente peligrosos. Implica probar que ese medio peligroso ha tenido incidencia en la idoneidad de la conducta para posibilitar la lesión del bien jurídico. Al respecto Corcoy Bidasolo (2007: 103). De allí que el núcleo de la conducta realizada por el sujeto recaiga sobre un "medio" que es positivamente delimitado y además genere una situación de peligro para el bien jurídico. 
(Silva Sánchez 2012: 53; Martínez Buján-Pérez 2005: 822). En efecto, no se sanciona cualquier conducta que pueda causar graves daños al medio ambiente o a los recursos naturales, sino que se debe determinar una serie de procesos resultativos, presididos por los verbos reseñados, de forma que, desde la perspectiva del interés tutelable, éstos serán medios precisos para la puesta en peligro. Lo anterior es importante no solo porque la realización típica requiere la constatación de uno de los referidos procesos sino por la definición del momento consumativo del delito. ${ }^{20}$

Bien jurídico. A día de hoy, cabe afirmar que es mayoritaria la tesis de la necesidad y posibilidad de vincular la teoría del bien jurídico crítica hacia la legislación a la Constitución. En este sentido, un precepto penal que no protege bienes jurídicos puede llegar a ser inconstitucional en cuanta intervención inadecuada, excesiva y, con ello, desproporcionada para la libertad del ciudadano (Roxin 2013: 24). Coherentemente, para formular el bien jurídico tutelable en el medio ambiente, deben ajustarse mínimamente sus contenidos conforme al principio de legalidad, necesidad, proporcionalidad (en su versión estricta y amplia), intervención mínima y exclusiva protección de bienes jurídicos (Mir Piug 2011).

Hace ya bastante tiempo se viene sosteniendo el bien jurídico debe cumplir varias funciones: i) una función de límite a la potestad punitiva del Estado, en cuya base se exige al legislador que oriente su actividad a la producción de normas penales que protejan exclusivamente bienes jurídicos; ii) una función de carácter teleológico en el sentido de constituir un criterio de interpretación de los tipos penales que condicionará su sentido y alcance ${ }^{21}$; iii) una función exegética, esto es, que constituye uno de los puntos de vista para concebir el núcleo material del injusto -común a todo comportamiento antijurídico- otorgando contenido a la tipicidad y a la antijuridicidad; y, iv) una función garantizadora que sólo se puede hacer efectiva en la medida que la teoría del bien jurídico sea capaz de indicar qué y por qué se protege (Hormazábal Malareé 1992: 9; Mir Piug 1994: 78).

20 Este momento fija el límite de la intervención penal en el hecho a título de participación, pues comúnmente se entiende que ésta no es posible en la fase de agotamiento del delito. Y, asimismo, dicho momento establece el punto de partida del cómputo de la prescripción.

21 Por eso, señala Jescheck, de ésta función emana el criterio sistemático de agrupar los delitos en la parte especial y más allá de la ordenación global, sigue la idea básica de que a través de la agrupación y clasificación de los bienes jurídicos, debe ser alcanzado un orden jerárquico de los valores protegidos. Jescheck \& Weigend (2002: 277). 
No es este el espacio para buscar el fundamento de legitimación del bien jurídico del medio ambiente acorde con la infinidad de posturas que en la historia se han defendido (Feuerbach, Birnbaum, Binding, Liszt, Welzel, Mayer, Amelung, Mezger, Roxin, Jakobs, Hirsch, Stratenwerth, Hefendehl, etc.); basta mencionar que el criterio de necesidad, por su carácter no abstracto y su relación con la idea de valor, sea el criterio de definición del bien jurídico que consideramos más aconsejable:

Todas las necesidades son necesidades de algo, y no se manifiestan nunca idealmente en un sentido abstracto puro. De esta forma todo aquello -y sólo aquello-de lo que una persona puede tener necesidad ha de ser considerado como un bien, en tanto merezca estimación positiva en el plano objetivo del ordenamiento jurídico. Únicamente en el supuesto de una valoración de este signo, y dentro de las condiciones estructurales indicadas, cabe entender como bien, en sentido jurídico-penal, precisamente lo que es susceptible de satisfacer una necesidad humana. ${ }^{22}$

El primer paso para configurar el contenido del bien jurídico ya está dado. Se reconoce la necesidad de protección del medio ambiente ${ }^{23}$, como una necesidad existencial, esto es, constante y universal sin la cual el hombre no podría conservarse como ser natural, sin que ello constituya un concepto de recogida de elementos y fenómenos naturales. El segundo paso para la configuración del bien jurídico está conformado por el reconocimiento expreso de la protección jurídica y social del ambiente -por supuesto, a través de la Constitución- con el claro propósito de adoptar medidas positivas de promoción y medidas negativas de represión de las conductas que lo lesionen o menoscaben (De la Cuesta Aguado 1996: 267-269). En relación a este punto, la Constitución Política de Colombia materializa un cúmulo de disposiciones que, entendidas sistemáticamente, denotan la importancia del ambiente como bien constitucional, cuya protección se garantiza a través de su consagración como principio fundamental, derecho y deber. ${ }^{24}$

22 Terradillos Basoco (1981, p.136). Igualmente, Hormazábal Malareé (1992: 53).

23 La estructura polifacética e interrelacional del concepto de medio ambiente obliga a configurarlo como un bien jurídico pluridimensional. Al respecto, Polaino Navarrete (1993: 867 y 876).

24 En este sentido, la sentencia T-411/92 - reiterada por la C-666/10 - de la Corte Constitucional colombiana 
De este modo, el último paso a seguir es otorgar su defensa -frente a los ataques más graves a las condiciones de satisfacción de las necesidades existenciales- al Derecho Penal. La definición del medio ambiente desde una perspectiva jurídico-penal no es, en modo alguno, una tarea fácil, siendo numerosas las definiciones y opiniones vertidas hasta la fecha acerca de lo que se entiende por tal bien jurídico. El Tribunal Constitucional español en Sentencia n. ${ }^{\circ}$ 102/95, de 26 de junio, tras indicar que la expresión-medio ambiente- es una redundancia debido al empleo de dos expresiones medio y ambiente que son sinónimos, acaba concluyendo que el medio ambiente, como objeto de conocimiento desde una perspectiva jurídica, estaría compuesto por los recursos naturales, entre los que tradicionalmente se incluyen la flora y fauna y los tres reinos clásicos de la naturaleza (suelo, aire, agua) y a los que se han ido incorporando otros elementos que no son naturaleza como el patrimonio histórico artístico y el paisaje.

La amplitud del concepto de ambiente se extrae también de las declaraciones internacionales que han adquirido una posición paradigmática al definir dicho concepto. En este sentido es de resaltar la declaración de Estocolmo sobre el Medio Ambiente Humano $(1972)^{25}$ que dentro de los recursos naturales incluye la Tierra, el aire, el agua, la flora y la fauna y especialmente muestras representativas de los ecosistemas naturales ${ }^{26}$ deben preservarse en beneficio de las generaciones presentes y futuras ${ }^{27}$, mediante una cuidadosa planificación y ordenación, según convenga. En similar sentido, la Comisión de la Unión Europea, en su Recomendación 2001/453/CE, de 30 de mayo de 2001 relativa al

desarrolló un concepto que resulta ser fundamental para la comprensión del bien jurídico del medio ambiente. Este concepto es el de la Constitución ecológica, respecto del cual manifestó: "(...) de una lectura sistemática, axiológica y finalista surge el concepto de Constitución Ecológica".

25 El hombre tiene el derecho fundamental al disfrute de condiciones de vida adecuadas en un medio de calidad tal que le permita llevar una vida digna y gozar de bienestar, y tiene la solemne obligación de proteger y mejorar el medio para las generaciones presentes y futuras.

26 Desde la ecología, el concepto de ecosistema está considerado como el más comprensivo y generalizado de los conceptos elaborados, aunque es un concepto excesivamente genérico y útil sólo como punto de referencia. Al respecto, De la Mata Barranco (1996: 47).

27 En efecto, no parece que haya obstáculo de asumir con Schünemann que la idea de -supervivencia de la especie humana- constituye un principio regulatorio superior -de oberstes Wert (valor supremo) habla este autor- y a partir de allí consagrar los subprincipios relativos a una participación relativamente igualitaria de todas las generaciones en los recursos naturales y, en fin, a una necesidad de conservación y mantenimiento de un medio ambiente lebensfreundlich und lebenswert (favorable y valioso para la vida). Cfr. Silva Sánchez (1997: 1715). 
reconocimiento, la medición y la publicación de las cuestiones medioambientales en las cuentas anuales y los informes anuales de las empresas define al medio ambiente (art. 2) como el entorno físico natural, incluidos el aire, el agua, la tierra, la flora, la fauna y los recursos no renovables, tales como los combustibles fósiles y minerales.

De igual forma, desde el derecho comparado ${ }^{28}$, en Alemania se entiende por medio ambiente los diversos medios (agua, suelo, aire), además de sus otras formas de manifestación (mundo animal y vegetal) pero sin olvidar la vinculación con el ser humano ${ }^{29}$; en Italia, frente a la noción de ambiente, absolutamente vaga y cambiante, no parece que el legislador haya querido dar una definición precisa y definitiva de este término que se utiliza con frecuencia (Palazzo 1999: 73; Ramacci 2007: 3) ${ }^{30}$ En España, el medio ambiente se ha definido como el conjunto de relaciones, reglas, ecosistemas, y funciones que han permitido la aparición y el mantenimiento de la vida, y como una parte de ella de la vida humana, en el planeta tierra, de forma que cada uno de los objetos (ríos, tierra, aire, etc.) son objetos en los que se manifiesta el bien jurídico protegido y a la vez, son parte integrante del mismo (De la Cuesta Aguado 1996: 277). También se ha dicho que el medio ambiente es el conjunto equilibrado de recursos naturales, interrelacionados entre si formando los ecosistemas, sobre el que se precisa una actuación efectiva a fin de que todo el sistema natural en su conjunto se conserve y evolucione en ese equilibrio y así pueda lograrse una calidad de vida y un desarrollo de la persona adecuados (Matellanes Rodríguez 2008: 48). Se entiende por medio ambiente el hábitat humano, natural o artificial, en el que el ciudadano desarrolla su vida y le da soporte, ${ }^{31}$ definición que tiende a ser excesivamente amplia (Suárez-Mira Rodríguez 2011: 59); y también

28 Estudia la protección penal del medio ambiente desde el Derecho comparado: Conde-Pumpido Tourón (1992: 26 y ss). Analiza las sanciones penales y administrativas en el ilícito ecológico desde el Derecho comparado Terradillos Basoco (1992: 79-81).

29 Por ello se dice que una concepción ecocéntrica del bien jurídico no se podría compatibilizar con la tarea del derecho penal, que debe hacerse cargo de la conducta dañosa para la sociedad y, con ello, para los miembros de ella. Hefendehl (2008: 7).

30 Se sostiene que con carácter urgente se necesita revisar la regulación de los depósitos de minerales (minas y canteras) para determinar su importancia estratégica para la economía nacional, la investigación y la identificación de estos recursos en el territorio (Sertorio 2013: 49).

31 Definición ciertamente homocéntrica según Queralt Jiménez (2010: 926) y Hava García (2011: 1040). 
se entiende como el conjunto de elementos y particularidades físicas que rodean los seres vivos ${ }^{32}$ y como el mantenimiento de las propiedades del suelo, el aire y el agua, así como la fauna y flora y las condiciones ambientales del desarrollo de estas especies, de tal forma que el sistema ecológico se mantenga con subsistemas subordinados y no sufra alteraciones perjudiciales. ${ }^{33}$

Ahora bien, el concepto de medio ambiente que se contempla en la Carta Magna colombiana es un concepto complejo, en donde se involucran los distintos elementos que se conjugan para conformar el entorno en el que se desarrolla la vida de los seres humanos, dentro de los que se cuenta la flora y la fauna que se encuentra en el territorio. Entiende la Corte Constitucional que los elementos integrantes del concepto de medio ambiente pueden protegerse per se y no, simplemente, porque sean útiles o necesarios para el desarrollo de la vida humana. En efecto, señala el alto Tribunal, que la protección del ambiente supera la mera noción utilitarista, para asumir una postura de respeto y cuidado que hunde sus raíces en concepciones ontológicas, es decir, la constitución ecológica adelanta ya un sistema constitucional basado en una clara visión ecocéntrica del bien jurídico.

Sin embargo, algunos autores sostienen que el bien jurídico del medio ambiente se erige como una realidad o fin necesario para la vida en sociedad -libre y segura- que garantiza los derechos humanos y fundamentales del individuo - sin confundirse con ellos-. En palabras de Silva Sánchez, procede constatar la existencia de un acuerdo, aunque éste sea de alcance limitado, acerca de que el medio ambiente no se puede proteger por sí mismo, sino sólo en tanto que condición necesaria para el desarrollo de la vida humana (Silva Sánchez 1997: 1715; Kühlen 1993: 701-704). Se trata de un bien jurídico de corte personal que incluye bienes de la pero que sólo los declara legítimos cuando en última instancia sirvan al ciudadano (Roxin 2007: 448). Conforme a lo anterior, aunque es uno de los bienes más difíciles de precisar, dado el importante debate que han suscitado en el

32 En otras palabras es el conjunto de condiciones físicas para la vida-clima, luz, temperatura, agua, nutrientes, suelo, etc.-(Silva Sánchez 2012: 26; Alastuey Dobón 2004: 57).

33 Concepto que, desde una perspectiva global, le añade la ecología del territorio, esto es, la protección del urbanismo y la ordenación del territorio. Berdugo Gómez de La Torre (1992: 47). En iguales términos: Cantarero Bandrés (1992: 72); Conde-Pumpido Tourón (1992: 17); Terradillos Basoco (2008: 370). En contra De la Mata Barranco (1996: 50). 
Derecho las concepciones más o menos antropocéntricas del medio ambiente ${ }^{34}$, lo cierto es que en Colombia, el bien jurídico del medio ambiente no aparece como objeto de tutela en un contexto claramente antropocéntrico, autónomo y colectivo (supraindividual). Aunque el art. 45 de la Constitución Política se refiera al derecho de disfrutar de un medio ambiente sano y adecuado para el desarrollo de la persona ${ }^{35}$, siendo deber del Estado proteger la diversidad e integridad del ambiente, conservar las áreas de especial importancia ecológica y fomentar la educación para el logro de estos fines, así como velar por la utilización racional de todos los recursos naturales, con el fin de proteger y mejorar la calidad de la vida a través de una indispensable solidaridad colectiva, el motivo principal para criminalizar conductas que atentan contra el medio ambiente tiene fundamento en una dimensión claramente ecocéntrica.

De la propia definición del Capítulo en que se enmarca el precepto "De los delitos contra los recursos naturales y el medio ambiente" se muestra una clara connotación instrumental sin referencia a la persona no obstante se diga que los elementos del medio natural constituyen un recurso siempre y cuando tenga utilidad para el ser humano (Silva Sánchez 2012: 25). ${ }^{36}$ Usualmente, se ha dicho que las tesis antropocéntricas tienen dos vertientes: la radical, que considera al medio ambiente sólo como un instrumento de ataque a los bienes jurídicos individuales clásicos, sin que en absoluto pueda ser elevado por sí mismo al rango de bien jurídico (Alastuey Dobón 2004); y, la moderada, en la que el medio ambiente es un bien jurídico de carácter colectivo que

34 La opción entre antropocentrismo y ecocentrismo reclama otra contraposición, mucho más general e importante, referida a la alternativa entre la tutela de bienes o la tutela de funciones. En efecto, "el proceso de transformación progresiva de la tutela de bienes a la tutela de funciones que inspira la dinámica de la producción legislativa más reciente en materia penal, es un camino muy arriesgado, pues se opone diametralmente al eje del principio de ofensividad -y, más aún, al de subsidiariedad-y por consiguiente, es ajeno a la función de garantía que el bien jurídico en sentido real aún está destinado a desempeñar dentro del ejercicio de la potestad punitiva" (Moccia 1997: 113; Palazzo 1999: 75; Silva Sánchez 2012: 24).

35 La Corte Constitucional ha sostenido que el medio ambiente tiene el carácter de derecho fundamental por conexidad, - al resultar ligado indefectiblemente con los derechos individuales a la vida y a la salud de las personas-. C-632/11. Puede consultarse además, C-595/10; T-092/93; C-432/00; C-671/ 01; C-293/02; C-339/02; C-486/09. El carácter de derecho fundamental del medio ambiente, dada su relación con derechos de esa índole, fue reiterado por la Corte, entre muchas otras, en las Sentencias C-432/00, C-671/01, C-293/02 y C-595/10.

36 A veces se presenta legislativamente una dimensión instrumental pero a veces no -a no ser que se quiera sostener genéricamente que toda protección del medio ambiente es siempre protección de la vida en cuyo caso pierde su sentido la discusión en torno a un concepto antropocéntrico o ecocéntrico-(Alonso Álamo 2008: 27). 
goza de relativa autonomía respecto de los bienes jurídicos individuales pues se admite su existencia sólo en la medida que tales bienes son concebidos como instrumento de protección de los bienes jurídicos individuales. Entendemos que sobre la base de éstas disquisiciones se encuentra la teoría monista personalista del bien jurídico según la cual los intereses generales sólo pueden reconocerse legítimamente en la medida en que sirvan a los intereses personales. ${ }^{37}$

Por otro lado, el carácter ecocéntrico del bien jurídico permite rescatar cierta autonomía al bien jurídico del medio ambiente por lo que no es necesario que los tipos que los protejan se refieran a los bienes individuales. Es decir, el bien jurídico estaría conformado por las condiciones naturales que influyen en la tierra, fauna, flora, etc. que para ponerlas en peligro no sería preciso corroborar el peligro para bienes individuales. Esta opción aboga por la consideración del medio ambiente como un bien jurídico de carácter colectivo que presenta autonomía respecto de determinados bienes jurídicos supraindividuales como la vida, salud o la integridad. Igual que la teoría anterior, se identifica según se defienda la protección del medio ambiente por las funciones que cumple para el desarrollo de la vida humana -versión moderada- o se defienda la protección del medio ambiente por sí mismo -versión radical- (Alastuey Dobón 2004: 33-36; Conde-Pumpido Tourón 1992: 16) ${ }^{38}$ La radical tiene apoyo en penalistas españoles como Conde-Pumpido Tourón y Martínez Buján-Pérez, al señalar que el medio ambiente, como objeto de protección penal, es el mantenimiento de las propiedades del suelo, el aire y el agua, así como la fauna y la flora, y de las condiciones ambientales de desarrollo de estas especies,

37 En lo que al medio ambiente se refiere, los partidarios de la escuela de Frankfurt y el -concepto personal de bien jurídico-, guiados por Hassemer, entienden que la mayoría de los tipos del Derecho penal medioambiental deben eliminarse quedando como mero ilícito administrativo, pues tales tipos muestran un alejamiento de la protección -como delitos de peligro- de la vida y la integridad corporal de las personas (Silva Sánchez 1997: 1715; Muñoz Conde \& Hassemer 1989: 109; De la Cuesta Aguado 1995a: 20; Portilla Contreras 2008: 289; Rodas Monsalve 1993: 255). En el CP español para que pueda afirmarse la relevancia jurídica de una conducta que afecte al medio ambiente no será necesario afirmar que la afectación aunque no sea de manera directa, incida o pueda incidir en el desarrollo (presente o fututo) de las personas (Silva Sánchez 2012: 27). En Colombia, también es así porque la inclusión de la constitución ecológica como objeto de protección avala la tesis de la afirmación de la autonomía de los bienes jurídicos medioambientales. Por todos, Terradillos Basoco (2008: 372), concibe una posición ecocéntrica moderadas (Fuentes Osorio 2012: 12).

38 La principal crítica al ecocentrismo radical consiste en que no se trata de proteger el medio ambiente contra el ser humano (De la Mata Barranco 1996: 52). 
de tal forma que el sistema ecológico se mantenga con sus sistemas subordinados y no sufra alteraciones perjudiciales (Martínez Buján-Pérez 2005: 821; Conde-Pumpido Tourón 1992: 17). ${ }^{39}$ Respecto a la teoría ecocéntrica moderada, lo verdaderamente especifico como bien jurídico, lo que distingue sustancialmente al medio ambiente de los demás bienes jurídicos colectivos, es que su relación con los bienes individuales no se limita a aquellos de los que son portadores las generaciones actuales sino que trasciende a éstas, pues el medio ambiente es condición de la vida de las generaciones futuras, no sólo en el sentido de su subsistencia, sino también en lo que respecta al ejercicio de los bienes jurídicos de esas generaciones (Alastuey Dobón 2004: 39; Alcácer Guirao 2002: 2).

Parte de la doctrina considera que las fundamentaciones y discusiones acerca de la referencia al hombre en el bien jurídico del medio ambiente, en base a la indicación teleológica contenida en la Constitución son discusiones vanas, no por falsas, sino por inútiles (De la Cuesta Aguado 1995: 91; De la misma 1996: 272). Y ello, con razón, porque por una u otra vía, en todo caso, primará la persona individual, bien sea porque al elevar a objeto de tutela penal factores como el agua, aire, tierra, flora o fauna, esto es, los recursos naturales en sí mismos considerados, la afectación de cualquiera de ellos repercute, a corto o medio plazo, en la condiciones de existencia de los individuos (Muñoz Conde 2010: 590; Suárez-Mira Rodríguez 2011: 85). O bien, situando ya la protección de los individuos de un modo más mediato mediante la consideración antropocéntrica. Por consiguiente, creemos que la vinculación al individuo, sea más o menos estrecha, es común a todo bien jurídico. Como diría Hormazábal: "Los bienes jurídicos no giran exclusivamente en tomo a una persona individual o de una colectividad considerada como globalidad, sino que están en función de las bases de existencia o de funcionamiento de un sistema de relaciones sociales democrático, esto es de vínculos entre personas realizadas en condiciones de libertad y dignidad" (Hormazábal Malareé 1992a: 154).

En efecto, que la protección de los bienes jurídicos universales tenga sentido sólo en la medida en que se les considere condiciones esenciales para el desarrollo de la persona, o si

39 La teoría también tiene algunos adeptos en Alemania e Italia: Kühlen (1993); Palazzo (1999: 75). En contra, Hormazábal Malareé (2001: 1425) entiende que "en la protección del medio ambiente como bien jurídico no se trata de proteger la naturaleza en cuanto valor en sí misma, sino en tanto que ella está al servicio del hombre y de las generaciones futuras. Se trata de proteger la naturaleza como una relación social. La protección de la naturaleza como valor abstracto desvinculada del hombre lleva a un fundamentalismo ecológico". 
se quiere, para el uso y disfrute personal de los bienes jurídicos individuales, no implica que cada bien jurídico supraindividual haya de conectarse con determinados bienes jurídicos individuales y que esa conexión haya de manifestarse de un modo expreso en la estructura de los tipos que los protegen (Alastuey Dobón 2004: 26-27). Una cosa es que todos los bienes jurídicos hayan de tener relación con el individuo y otra muy distinta es derivar de allí una dependencia de los bienes jurídicos colectivos a los individuales. Es más, como suele suceder, los modelos rara vez se presentan puros (Alonso Álamo 2008: 25), de allí que, en la actualidad, prime el carácter moderadamente antropo-ecocéntrico del medio ambiente frente a las versiones radicales de ambas teorías (Peris Riera 1984: 25; Terradillos Basoco 1995: 203; Vives Antón et al. 2010: 584; Mateos Rodríguez-Arias, 1998: 58; Silva Sánchez 1997: 1715; Box Reig 2012: 140; De la Mata Barranco 2010: 224; Suárez-Mira Rodríguez 2011: 57; Carmona Salgado 2005: 698; Fuentes Osorio 2010: 4; Matellanes Rodríguez 2008: 38; Alonso Álamo 2008: 26; Alcácer Guirao 2002: 3; Regis Prado 2008: 121; Muñoz Lorente (2000: 72; Rodríguez Ramos 1980-1981: 291; Polaino Navarrete 1993: 876; Paredes Castañón 1997: 220). No obstante, creemos, que debe primar una opción ecocéntrica y que es posible realizar el tipo del art. $338 \mathrm{CP}$ sin necesidad de comprobar que el comportamiento ha tenido repercusión en la salud de las personas. No creemos que el mínimo necesario para la intervención penal, esto es, la puesta en peligro del medio ambiente (en términos de peligro concreto o de peligro abstracto, entendido como peligrosidad de la conducta) tenga que conectarse con la existencia de una peligrosidad apreciable en la propia conducta, para la vida y salud de las personas.

Ciertamente, que ésta última peligrosidad hubiera de constatarse positivamente es cuestionado. Y, aunque se admita la estrecha conexión que existe entre la protección del medio ambiente y la protección de otros bienes personales -el medio ambiente está profundamente conectado con el individuo y tal conexión tiene un carácter medial: un medio ambiente adecuado es herramienta necesaria para que los derechos del individuo sean una realidad(Matellanes Rodríguez 2008: 40), una concepción ecocéntrica del ambiente reivindica el carácter autónomo del bien jurídico, que tutela los intereses humanos actuales y futuros orientados al desarrollo de las condiciones ambientales humanas pero, a su vez, una específica tutela ambiental, reconocida como objeto de protección en sí. Por ejemplo, en Colombia, el 
bien jurídico del medio ambiente está integrado por una multiplicidad de subsistemas ${ }^{40}$, que constituyen el objeto material de afectación y cuya perturbación es un criterio orientador. De allí se colige que en la tipificación de los comportamientos que atentan contra el medio ambiente el legislador haya optado por una protección ecocéntrica del medio ambiente; como la intervención penal no está condicionada por la generación de riesgos para bienes jurídicos individuales como la vida o la salud (Cadavid Quintero 2007: 220), lo anterior sugiere, necesariamente, que se debe considerar una postura ecocéntrica moderada (Ruiz López 2006: 190) en la que el medio ambiente se proteja por sí mismo -de manera independiente- pero cobije indirectamente las funciones que cumple para el desarrollo de la vida humana. Lo anterior no implica desechar, una orientación del sistema presidida por la finalidad antropocéntrica al estilo de Rodas Monsalve (Rodas Monsalve 1993: 93).

El medio ambiente, es algo más que un conjunto de elementos, es el conjunto de relaciones, reglas naturales, bióticas, biológicas, ecológicas, ecosistemas y funciones que han permitido la aparición y el mantenimiento de la vida -y como una parte de ella de la vida humana- en el planeta tierra (De la Cuesta Aguado 1995a: 156). Pero ello no quiere decir que estos elementos medioambientales no puedan ser merecedores de protección en sí. El suelo, subsuelo, los ríos y mares, piedras, etc. no son propiamente el bien jurídico tutelado, sino que lo será el medio ambiente como un todo; lo que sucede es que su protección se puede realizar a través de la protección de determinados elementos u objetos medioambientales, cuya integración en el sistema puede hacer que su puesta en peligro suponga, a su vez, la del medio ambiente como totalidad. ${ }^{41}$ Una cosa es el sustrato u objeto material de un bien jurídico y otra la valoración que se incorpora a ese objeto, que compone el auténtico contenido del concepto de bien jurídico. Cuando se produce un ataque sobre uno de los integrantes materiales que componen el medio ambiente, lo más seguro es que se esté afectando a todo el conjunto. Sin embargo ello no es siempre predicable. Existe la posibilidad inversa, esto es, que la actuación incida sobre un elemento ambiental, no repercuta en un posible daño sobre el conjunto, en cuyo caso habría que estimar que la conducta es atípica por no haber

40 En efecto, una mirada del Título XI del CP colombiano parece dar la idea de un catálogo amplio de tipos penales ordenados según el objeto material de la conducta: éstos se concretan en los recursos fáunicos, florísticos, hidrobiológicos.

41 Considera que la biodiversidad (definida como la variabilidad de organismos vivos y de complejos ecológicos de los que forman parte) puede ser considerada en sí misma un auténtico bien jurídico penal (Hava García 2008: 1019-1020). 
puesto en peligro el medio ambiente (Matellanes Rodríguez 2008: 45).

En definitiva, el reconocimiento del medio ambiente como un bien jurídico autónomo, la ampliación del número de figuras delictivas y la inclusión de los elementos bióticos que lo conforman (Muñoz Conde 2013: 252), supone una mejora en su protección. Que ello se haya o no practicado correctamente es cuestión aparte. La estulticia jurídica que niega el carácter jurídico penal del medio ambiente hoy, más que nunca, choca con la ampliación del catálogo de los objetos de tutela y con la configuración de conductas que los afectan y reafirma la necesidad -criterio legitimante de protección- de concretar el contenido del bien jurídico tutelable.

Aunque no resulta muy acertada la rúbrica que el legislador colombiano hace en este punto cuando intenta proteger al medio ambiente y a los recursos naturales, como si se tratara de realidades distintas, ello marca una doble pauta en la configuración del bien jurídico, tutelando por un lado - en sentido amplio- el medio ambiente, y por otro, los recursos naturales - que serían objeto de tutela en sí mismos considerados, como bienes jurídicos autónomos- (Terradillos Basoco 1997; Hava García 2011: 1038); si bien la mayoría de las conductas que se regulan en el Capítulo único del Título XI, implican la creación de un peligro para el medio ambiente a través de un ataque al medio ambiente o bien mediante la afectación de cualquiera de los subsistemas que lo conforman (básicamente agua, aire y suelo), impera separar ambas nociones del todo a la parte.

Por último, debe mencionarse que el bien jurídico del medio ambiente se define como un bien de carácter colectivo o supraindividual en donde el sujeto pasivo de la conducta punible se constituye a partir de una pluralidad de individuos indeterminados. Estos bienes colectivos se han caracterizado por ser bienes de titularidad compartida, de carácter indisponible e indivisible (Soto Navarro 2003). Para Bustos Ramírez, estos bienes jurídicos se caracterizarían porque no tienen una referencia micro-social, sino que están en relación con el funcionamiento del sistema social. Afirma, que se trata de bienes jurídicos que tienen una dimensión macro-social. Expresamente:

La protección de estos bienes jurídicos tiene por objetivo la mantención de las condiciones de seguridad para que los bienes jurídicos microsociales puedan desarrollarse. En consecuencia, entre estos bienes jurídicos colectivos y los bienes jurídicos microsociales, hay una relación teleológica. El que contamina 
el medio ambiente, pone condiciones de peligro para la vida y la salud de las personas (Bustos Ramírez 2006: 252).

De esta manera, no es necesario que se ponga en peligro el bien jurídico individual, basta con la puesta en peligro del bien jurídico colectivo que está en una relación teleológica con los bienes jurídicos individuales. De allí que la protección de un bien jurídico colectivo pueda adoptar la forma de delito de lesión o de delitos de peligro. Entonces, no toda vez que haya un precepto que proteja un bien jurídico colectivo, necesariamente ha de existir un delito de peligro (Bustos Ramírez 2006: 252). ${ }^{42}$

$\mathrm{Al}$ fin de cuentas, considerando que no hay dubitaciones acerca del reconocimiento de la protección penal del medio ambiente, téngase en cuenta que ello debe hacerse con sumo cuidado. Como señala Terradillos Basoco: "la reivindicación de una intervención penal eficaz no puede confundirse con una inútil huida al Derecho penal" (Terradillos Basoco 1995: 199). De modo que, una radical (Müller-Tuckfeld 2000) marcha atrás, en el sentido de suprimir totalmente los delitos medioambientales es materialmente discutible, puesto que las conductas más graves que lesionen o pongan en peligro el bien jurídico deben, a día de hoy, situarse dentro de la zona central del Derecho penal (Alonso Álamo 2008: 35). En definitiva, la naturaleza colectiva del medio ambiente y las graves repercusiones que su menoscabo pueda acarrear tanto en el orden nacional como internacional, desencadenan la importancia que merece ésta necesidad.

\section{Conclusiones}

En las últimas décadas del siglo XX se refleja ya en la legislación y en la jurisprudencia, una nueva correlación entre sociedad y naturaleza. Hay otra percepción de la naturaleza y sus recursos. Esta nueva percepción, que se adquiere primeramente en la ecología, política y por supuesto en la sensibilidad social, acaba por reflejarse en el Derecho y, particularmente, en el derecho penal. Aquí ha podido hablarse de la protección del medio

42 La tutela penal requiere, para ser verdaderamente eficaz, que la consumación se anticipe al momento de producción de un resultado de perjuicio efectivo y concreto, lo que, en principio, no tiene por qué ser contrario al principio de intervención mínima siempre y cuando tal anticipación se mantenga dentro de unas coordenadas razonables de proximidad del peligro representado por la conducta a la efectiva producción de la lesión de dicho bien jurídico (Huerta Tocildo 2001: 42). 
ambiente y los recursos naturales. Y, si hubiera de ofrecerse un elemento que caracterice aquella concienciación, sin duda sería en relación a la minería ilegal: sus recursos (suelo, agua, minerales, etc.) han dejado de ser objetos sobre los que dispone con cierto límite. Hoy, debe reconocer que estos objetos cuentan con una protección propia -y sólo, en segundo plano, están vinculados con los bienes de la vida o la salud de las personas-.

Esta pretendida orientación ecológica, que dispone la Constitución y sobre la que se pronuncia la jurisprudencia es caldo de cultivo para las interpretaciones que sobre el art. 338 quiera disponerse. De lo que se trata, entonces, es de apreciar que el tipo no se arrogue a otros bienes jurídicos que ya cuentan con protección autónoma. Con estas consideraciones generales, impera encuadrar el estudio de los diferentes recursos naturales dentro de una vertiente ecocéntrica para luego adentrarse al estudio de particularidades técnicas del tipo como el contenido del injusto, la tipicidad subjetiva, las leyes penales en blanco, el principio del non bis in idem, etc.

\section{Bibliografía}

Abello, C. (2012). Consulta previa en casos de minería para comunidades indígenas y tribales. Trans-pasando Fronteras, (2), 111-124. doi:http://dx.doi.org/10.18046/ retf.i2.1322

Acale Sánchez, M. (2009). En AA.VV, A. Nieto Martín, \& O. Mejía Patiño (eds.), Estudios de Derecho Penal económico (pp. 207-255). Ibagué: Universidad de Ibagué / Universidad Castilla la Mancha.

Acosta M., A. D. (19 de Febrero de 2012). Razón pública. Recuperado el 15 de julio de 2013, de http://www.razonpublica.com/index.php/econom-y-sociedad-temas-29/2736ilegalidad-y-criminalidad-en-la-mineria-pescando-en-rio-revuelto.html

Alastuey Dobón, M. C. (2004). El delito de contaminación ambiental (Artículo 325.1 del Código Penal). Granada: Comares.

Alcácer Guirao, R. (2002). La protección del futuro y de los daños cumulativos. RECPC, $4(8), 1-30$.

Alonso Álamo, M. (2008). La aporía del Derecho penal del medio ambiente. En Quintero Olivares, \& Morales Prats, Estudios de Derecho Ambiental (pp. 21-40). Valencia: Tirant Lo Blanch. 
ANDI. (Diciembre de 2012). Colombia: Balance 2012 y perspectivas 2013. Recuperado el 1 de Septiembre de 2013, de http://www.larepublica.co/sites/default/files/larepublica/andi.pdf

Anuario Estadístico Minero Colombiano-Ministerio De Minas Y Energía. (2012). www. simco.gov.co. Recuperado el 15 de junio de 2013, de Sistema de información minero colombiano SIMCO: http://www.simco.gov.co/LinkClick.aspx?fileticke $\mathrm{t}=\mathrm{rDDN} 5 \mathrm{zSCgEo} \% 3 \mathrm{D} \& \mathrm{tabid}=96$

Arroyo Zapatero, L., Berdugo Gómez De La Torre, I., Ferré Olivé, J. C., García Rivas, N., Serrano Piedecasas, J. R., \& Terradillos Basoco, J. M. (2007). Comentarios al Código Penal (1 ed.). Madrid: Iustel.

Bacigalupo, E. (1982). La instrumentalización técnico-legislativa de la protección del medio ambiente. Estudios penales y Criminológicos, 193-213.

Berdugo Gómez De La Torre, I. (1992). El medio ambiente como bien jurídico tutelado. En J. M. Terradillos Basoco, El delito ecológico (pp. 41-50). Madrid: Trotta.

Berdugo Gómez De La Torre, I. (2008). La protección penal del medio ambiente. Algunas cuestiones generales. En F. Muñoz Conde, Problemas actuales del Derecho Penal y de la criminología. Estudios penales en memoria de la profesora Dra. María del Mar Díaz Pita (pp. 997-1008). Valencia: Tirant Lo Blanch.

Box Reig, J. (2012). Derecho penal. Parte Especial (1 ed., Vol. III). Madrid: Iustel.

Bricola, F. (1984). Tecniche di tutela penale e tecniche alternative di tutela. En M. De Acutis, \& G. Palombarini, Funzioni e limiti del diritto penale (pp. 3-84). Bolognia: Cedam Padova.

Bustos Ramírez, J. (2006). Lecciones de derecho penal, Parte General. Madrid: Trotta.

Cadavid Quintero, A. (2007). La protección penal del medio ambiente en el derecho penal colombiano. En J. M. Terradillos Basoco, \& M. Acale Sánchez, Nuevas tendencias en Derecho penal económico. Seminario Internacional de Derecho Penal (Jerez 24, 25 y 26 de septiembre de 2007) (pp. 213-229). Jerez de la Frontera: Universidad de Cádiz.

Cantarero Bandrés, R. (1992). El delito ecológico: análisis del actual tipo penal y sus antecedentes. En J. M. Terradillos Basoco, El delito ecológico (pp. 67-78). Madrid: Trotta.

Carmona Salgado, C. (2005). Delitos contra los recursos naturales, el medio ambiente, la flora, 
la fauna y los animales domésticos. Disposiciones comunes. En M. COBO DEL ROSAL, Derecho Penal Español. Parte Especial (pp. 695-717). Madrid: Dykinson.

Conde-Pumpido Touron, C. (1992). Introducción al delito ecológico. En J. M. Terradillos Basoco, El delito ecológico (pp. 13-49). Jerez de la Frontera: Trotta.

Corcoy Bidasolo, M. (2007). Algunas cuestiones sobre el injusto típico en los “delitos de peligro". Revista de Derecho Penal(2), 81-118.

Cugat Mauri, M. (2008). El límite de adecuación social de las conductas contaminantes. En Quinterio Olivares, \& Morales Prats, Estudios de Derecho Ambiental. Libro homenaje al profesor Josep Miquel Prats Canut (pp. 445-467). Valencia: Tirant Lo Blanch.

DANE. (20 de junio de 2013). Boletín de prensa Número 13. Recuperado el 15 de julio de 2013, de Producto Interno Bruto Primer Trimestre 2013 Base 2005: http:// www.dane.gov.co/files/investigaciones/boletines/pib/bolet_PIB_Itrim13.pdf

De La Cuesta Aguado, M. (1996). Algunas consideraciones sobre acerca de la necesidad de protección del medio ambiente como bien jurídico. Anales de la Universidad de Cádiz, 267-282.

De La Cuesta Aguado, M. (1995a). Causalidad en los delitos contra el medio ambiente. Valencia: Tirant Lo Blanch.

De La Cuesta Aguado, M. (1995b). La prueba en el delito ecológico. Madrid: Tecnos.

De La Cuesta Arzamendi, J. (1999). Cuestiones dogmáticas relativas al delito de contaminación ambiental. Revista Penal, 30-41.

De La Mata Barranco, N. J. (1996). Protección Penal del Ambiente y Accesoriedad Administrativa. Tratamiento penal de comportamientos perjudiciales para el ambiente amparados en una autorización administrativa ilícita. Barcelona: Cedecs.

De La Mata Barranco, N. J. (2010). Protección penal del ambiente. En J. R. SERRANO PIEDECASAS, \& E. DEMETRIO CRESPO, Cuestiones actuales de derecho penal empresarial (pp. 221-245). Madrid: Colex.

Departamento Administrativo Nacional de Estadística. (20 de Junio de 2013). DANE. Recuperado el 20 de Julio de 2013, de Producto Inerno Bruto. Primer trimestre de 2013 - Base 2005: http://www.dane.gov.co/files/investigaciones/boletines/pib/cp_PIB_Itrim13.pdf 
Departamento Nacional De Planeación. (16 de junio de 2010). www.dnp.gov.co. Recuperado el 14 de junio de 2013, de Plan Nacional de Desarrollo 2010-2014: https:// www.dnp.gov.co/PND/PND20102014.aspx

Esteve Pardo, J. (2006). Derecho y medio ambiente: problemas generales. El Derecho del medio ambiente como Derecho de decisión y gestión de riesgos. REDUR(4), 7-16.

Fernández Posada, E. (2012). Minería ilegal a la luz de la ley penal colombiana. En AA/VV, Libro Homenaje a Juan Fernández Carrasquilla. Medellín: Universidad de Medellín.

Fuentes Osorio, J. (2012). ¿Delito ecológico como delito de peligro abstracto? RECPC(14-17), 1-49.

Fuentes Osorio, J. (2010). ¿Delito medioambiental como delito de lesión? Revista Catalana De Dret Ambiental, I(2), 1-61.

González-Ripoll Garzón, J. (1992). Sociología del delito ambiental. Córdoba: Servicio de publicaciones Universidad de Córdoba.

Hassemer, W. (1995). Derecho penal simbólico y protección de bienes jurídicos. En AA.VV, Pena y Estado (E. LARRAURI, Trad., pp. 23-36). Santiago de Chile: Conosur.

Hava García, E. (2008). Delitos relativos a la protección de la flora y fauna: diez años de vigencia. En Quintero Olivares, \& Morales Prats, Estudios de Derecho Ambiental. Homenaje al profesor Jose Miquel Prats Canut (pp. 1015-1032). Valencia : Tirant Lo Blanch.

Hava García, E. (2011). Delitos contra los recursos naturales y el medio ambiente. En AAVV, Derecho Penal Económico y de la empresa. Parte especial (3 ed., pp. 1030-1082). Valencia: Tirant Lo Blanch.

Hefendehl, R. (2008). Derecho penal medioambiental: ¿Por qué o cómo? Estudios públicos(110), 1-27.

Heine, G. (1993). Accesoriedad administrativa en el Derecho Penal del Medio Ambiente. $A D P C P$, fasc. I(t. XLVI), 289-315.

Hormazábal Malareé, H. (1992). Delito ecológico y función simbólica del derecho penal. En J. M. Terradillos Basoco, El delito ecológico (pp. 51-65). Madrid: Trotta.

Hormazabal Malareé, H. (1992a). Bien jurídico y Estado Social y Democrático de Derecho. El objeto protegido por la norma penal (2 ed.). Santiago de Chile: Cono sur. 
Hormazábal Malarée, H. (2001). El principio de lesividad y el delito ecológico. En Quintero Olivares, \& Morales Prats, El nuevo Derecho Penal Español. Estudios penales en memoria del Profesor José Manuel Valle Muñiz (pp. 14171428). Navarra: Aranzadi.

Huerta Tocildo, S. (2001). Principios básicos del Derecho Penal y art. 325 del Código Penal. Revista Penal(8), 39-52.

Jescheck, H. H., \& Weigend, T. (2002). Tratado de Derecho Penal. Parte General. (M. Olmedo Cardenete, Trad.) Granada: Comares.

KÜHLEN, L. (1993). Umweltstrafrecht-auf der Suche nach einer neuen Dogmatik. ZStW, 105(Heft 4), 697-726.

Lascuraín Sánchez, J. A. (2005). Elogio del artículo 325 del Código Penal. En A. J. BARREIRO, Estudios sobre la protección penal del medio ambiente en el ordenamiento jurídico español (pp. 265-294). Granada: Comares.

Marquès I Banqué (2011). Capítulo III. De los delitos contra los recursos naturales y el medio ambiente. En Quintero Olivares, \& Morales Prats, Comentarios al Código Penal Español (9 ed., Vol. tomo II, pp. 696-763). Pamplona: Cizur menor Aranzadi.

Martínez Buján-Pérez, C. (2005). Derecho Penal Económico y de la empresa. Parte especial (2 ed.). Valencia: Tirant Lo Blanch.

Matellanes Rodríguez, N. (2008). Derecho Penal del Medio Ambiente (1 ed.). Madrid: Iustel.

Mateos Rodríguez-Arias, A. (1998). Los delitos relativos a la protección del medio ambiente. Madrid: Colex.

Mendo Estrella, Á. (2008). La compleja estructura de peligro en el denominado delito "ecológico" del art. 325.1 del Código Penal: Algunas alternativas. Anuario de derecho penal y ciencias penales, t. 61(1), 237-264.

Mendoza Buergo, B. (2005). El delito ecológico: configuración típica, estructuras y modelos de tipificación. En A. J. Barreiro, Estudios sobre la protección penal del medio ambiente en el ordenamiento jurídico español (pp. 109-150). Granada: Comares.

Menéndez, A. (2005). El delito ambiental básico a la luz de la reciente jurisprudencia. En J. Carbonell Mateu, B. Del Rosal Blasco, L. Morillas Cueva, E. Orts Berenguer, \& M. Quintanar Díez, Estudios penales en homenaje al profesor COBO DEL 
ROSAL (pp. 635-643). Madrid: Dykinson.

Mir Piug, S. (1976). Introducción a las bases del Derecho Penal. Concepto y método. Barcelona: Bosch.

Mir Piug, S. (1994). El derecho penal en el Estado social y democrático de derecho (1 ed.). Barcelona: Ariel.

Mir Piug, S. (2003). Introducción a las bases del derecho penal. Concepto y método ( 2 ed.). Buenos Aires: BdeF.

Mir Piug, S. (2011). Derecho Penal. Parte General (9 ed.). Barcelona: Reppertor.

Moccia, S. (1997). De la tutela de bienes a la tutela de funciones: entre ilusiones postmodernas y reflejos iliberales. En J. M. Silva Sánchez, Política criminal y nuevo Derecho Penal. Libro homenaje a Claus Roxin (pp. 113-142). Barcelona: Bosch.

Morales Prats, F. (1997). La estructura del delito de contaminación ambiental. Dos cuestiones básicas: Ley Penal en blanco y concepto de peligro. En AA.VV, \& J. M. Valle Muñiz (Ed.), La protección jurídica del Medio Ambiente (pp. 225-269). Pamplona: Aranzadi.

Morales Prats, F. (2001). Función y contenido esencial de la norma penal: bases para una teoría dualista o bidimensional. En Quintero Olivares, \& Morales Prats, El nuevo Derecho Penal Español. Estudios penales en memoria del Profesor José Manuel Valle Muñiz (pp. 537-559). Navarra: Aranzadi.

Morales Prats, F. (2008). El delito de contaminación ambiental: análisis del artículo 325.1 CP. En Quintero Olivares, \& Morales Prats, Estudios de Derecho Ambiental. Libro homenajes al profesor Josep Miquel Prats Canut (pp. 1033-1066). Valencia: Tirant Lo Blanch.

Müller-Tuckfeld, J. C. (2000). Ensayo para la abolición del Derecho penal del medio ambiente. En AA.VV, La insostenible situación del Derecho Penal (pp. 507528). Granada: Comares.

Muñoz Conde, F. (2013). Manual de Derecho Penal Medioambiental. Valencia: Tirant Lo Blanch. (2010). Derecho Penal. Parte Especial (18 ed.). Valencia: Tirant Lo Blanch.

Muñoz Conde, F., \& García Arán, M. (2007). Derecho Penal. Parte General. Valencia: Tirant Lo Blanch. 
Muñoz Conde, F., \& Hassemer, W. (1989). Introducción a la Criminología y al Derecho Penal. Valencia: Tirant Lo Blanch.

Muñoz Lorente, J. (1999a). El delito ecológico: su carácter de delito permanente y la interpretación de la agravación de "clandestinidad". Vertidos indirectos en el suelo y subsuelo con riesgo de grave perjuicio para la salud de las personas. Revista de Gestión Ambiental(7), 67-70.

Palazzo, F. (1999). Principios fundamentales y opciones político-criminales en la tutela penal del ambiente en Italia. Revista Penal, 68-83.

Paredes Castañón, J. M. (1997). Responsabilidad penal y "nuevos riesgos": El caso de los delitos contra el medio ambiente. Actualidad Penal(1), 217-227.

Paredes Castañón, J. M. (2013). El Derecho penal español del medio ambiente: una evaluación crítica. En Álvarez García, Cobos Gómez De Linares, Gómez Pavón, Manjón-Cabeza Olmeda, \& Martínez Guerra, Libro homenaje al prof. Luis Rodríguez Ramos (pp. 751-771). Valencia: Trotta.

Peris Riera, J. M. (1984). Delitos contra el medio ambiente. Valencia: Universidad de Valencia.

Polaino Navarrete, M. (1993). La criminalidad ecológica en la legislación penal española. En AA.VV, Política criminal y reforma penal. Homenaje a la memoria del Prof. Dr. D. Juan del Rosal (pp. 855-884). Madrid: Edersa.

Portilla Contreras, G. (2008). La protección penal del derecho al medio ambiente y los derechos económicos sociales en un periodo de crisi del Derecho y del Estado de Derecho. En Quintero Olivares, \& Morales Prats, Estudios de Derecho Ambiental. Libro homenaje al profesor Josep Miquel Prats Canut (pp. 271-301). Valencia: Tirant Lo Blanch.

Prat García, J. M., \& Soler Matutes, P. (2000). El delito ecológico. Barcelona: Cedecs.

Prats Canut, J., Morán Mora, C., \& Marquès I Banqué (2002). Derecho Penal Ambiental y Derecho comunitario. La Directiva IP. Navarra: Aranzadi.

Ramacci, L. (2007). Diritto Penale dell' Ambiente. Verona: Casa Editrice Dott Antonio Milani.

Ramos Rodríguez, L. (2007). Delitos contra el medio ambiente (evolución y futuro). En F. Pérez Álvarez, “Universitas Vitae” Homenaje a Ruperto Núñez Barbero (pp. 627-648). Salamanca: Cise-Universidad de Salamanca. 
Regis Prado, L. (2008). El ambiente como bien jurídico penal: aspectos conceptuales delimitadores. Revista Penal, 109-124.

Rodas Monsalve, J. C. (1993). Protección Penal y Medio Ambiente. Barcelona: PPI.

Roxin, C. (1997). Derecho Penal. Parte general. Fundamentos. La estructura de la teoría del delito. (2 ed., Vol. tomo I). (D. Luzón Peña, M. Díaz Y García Conlledo, \& J. De Vicente Remesal, Trads.) Madrid: Civitas.

Roxin, C. (2007). ¿Es la protección de bienes jurídicos una finalidad del Derecho penal? En R. Hefendehl, La teoría del bien jurídico. ¿Fundamento de legitimación del Derecho penal o juego de abalorios dogmáticos? (pp. 443-458). Madrid-Barcelona: Marcial Pons.

Roxin, C. (2013). El concepto de bien jurídico como instrumento de crítica sometido a examen. RECPC, 1-27.

Ruiz López, C. (2006). Protección penal del medio ambiente. Derecho Penal y Criminología, 27(81), 173-194.

Ruíz Rodríguez, L. R. (2003). Las catástrofes medioambientales y la aplicación de la ley penal en el espacio. Eguzkilore. (17), 47-56.

Schünemann, B. (2002). Sobre la dogmática y la Politica criminal del Derecho Penal del medio ambiente. En B. Schünemann, Temas actuales y permanentes del Derecho penal después del milenio (pp. 203-223). Madrid: Tecnos.

Sertorio, M. (2013). Caractteristiche del Diritto Minerario Italiano. Rivista Giuridica dell'Ambiente(1), 23-49.

Silva Sánchez , J. M. (2012). Los delitos contra el medio ambiente. Barcelona: Atelier.

Silva Sánchez, J. M. (1997). ¿Protección penal del medio ambiente? Texto y contexto del artículo 325 del Código Penal. La Ley. Revista jurídica española de doctrina, jurisprudencia y bibliografia (3), 1714-1725.

Soto Navarro, S. (2003). La protección penal de los bienes colectivos en la sociedad moderna. Granada: Comares.

Sotomayor Acosta, J. O. (1999). Garantismo y Derecho penal en Colombia. Jueces para la Democracia (35), 92-98.

Terradillos Basoco , J. M. (1997). Delitos relativos a la protección del patrimonio y del medio ambiente. En J. M. Terradillos Basoco, Derecho penal del medio ambiente 
(pp. 35-57). Madrid: Trotta.

Terradillos Basoco, J. M. (1981). La satisfacción de necesidades como criterio de determinación del objeto de tutela jurídico-penal. Revista de la Facultad de Derecho de la Universidad Complutense(63), 123-149.

Terradillos Basoco, J. M. (1992). El ilícito ecológico: sanción penal-sanción administrativa. En J. M. Terradillos Basoco, El delito ecológico (pp. 79-105). Trotta: Madrid.

Terradillos Basoco, J. M. (1995). Derecho Penal de la Empresa. Madrid: Trotta.

Terradillos Basoco, J. M. (1996). Protección penal del medio ambiente en el nuevo Código Penal Español. Luces y sombras. Estudios Penales y Criminológicos(19), 289-327.

Terradillos Basoco, J. M. (1999). El derecho penal de la globalización: luces y sombras. En J. Capella Hernández, Transformaciones del Derecho en la mundialización (pp. 183-217). Madrid: CGPJ.

Terradillos Basoco, J. M. (2005). Artículo 325 del Código Penal. Lecturas jurisprudenciales. Técnicas de investigación e infracciones medioambientales, 127-160.

Terradillos Basoco, J. M. (2008). Protección penal del medio ambiente. Jurisprudencia e intuición. En Quintero Olivares, \& Morales Prats, Estudios de Derecho Ambiental. Libro homenaje al profesor Josep Miquel Prats Canut (pp. 365-393). Valencia: Tirant Lo Blanch.

Tiedemann, K. (1985). El nuevo Derecho penal español del ambiente en comparación con el Derecho penal alemán del ambiente. En A. Beristain, \& J. L. De La Cuesta, La droga en la sociedad actual. Nuevos horizontes en criminología (pp. 291301). San Sebastián: Caja de ahorros provincial de guipozcoa.

Vargas Valencia, F. (2013). Minería, conflicto armado y despojo de tierras: impactos, desafíos y posibles soluciones jurídicas. En L. J. Garay Salamanca, Minería en Colombia. Fundamentos para superar el modelo extractivista (pp. 57-88). Bogotá: Imprenta Nacional.

Velásquez V., F. (2009). Derecho Penal. Parte General. Medellín: Comlibros.

Vives Antón, T. S., Orts Berenguer, E., Carbonell Mateu, J. C., González Cussac, J., \& Martínez-Buján Pérez, C. (2010). Derecho Penal. Parte Especial (3 ed.). Valencia: Tirant Lo Blanch. 